\title{
IMPACTO ECONÔMICO DE EVENTOS: O GASTO DIRETO DOS TURISTAS EM PEQUENO DESTINO DO ESTADO DE MATO GROSSO
}

\section{ECONOMIC IMPACT OF EVENTS: THE DIRECT SPENDING OF TOURISTS IN A SMALL DESTINATION OF MATO GROSSO STATE}

\author{
Rita Maria de Paula Garcia ${ }^{1}$ \\ Roberto de Barros Mesquita ${ }^{2}$ \\ Ana Caroline Mocelin Marchetto ${ }^{3}$ \\ Emanuela Levorato Freire ${ }^{4}$
}

\begin{abstract}
RESUMO
Os eventos funcionam como instrumentos de expansão do potencial turístico e redutor dos efeitos da sazonalidade em comunidades receptoras. No município de Nova Xavantina, eventos do tipo rodeio são incentivados por investimentos públicos e privados como proposta de entretenimento à comunidade e indução do fluxo de visitantes e turistas. O artigo objetiva estimar o impacto econômico proveniente do gasto direto dos turistas frequentadores do evento, nos anos de 2018 e 2019. Empregou-se uma análise de impacto econômico com pesquisa de gastos com visitantes, conforme a taxonomia proposta por Stynes (1997, 1999). A investigação se classifica como descritiva com abordagem quantitativa. Identificou-se que o principal impacto foi causado pelos turistas que ficaram alojados nas casas de amigos e parentes, ou seja, gerando impactos significativamente menores no setor hoteleiro e nos atrativos turísticos.
\end{abstract}

Palavras-chave: Impactos econômicos do turismo, gasto turístico, evento turístico.

\begin{abstract}
The events work as instruments for expanding the tourism potential and reducing the effects of seasonality in receiving communities. In the municipality of Nova Xavantina, rodeo events encouraged by public and private investments as a proposal to entertain the community and induce the flow of visitors and tourists. The article aims to estimate the economic impact arising from the direct spending of tourists attending the event, in the years 2018 and 2019. An analysis of economic impact was used with visitor spending research, according to the taxonomy proposed by Stynes $(1997,1999)$. The investigation is classified as descriptive with a quantitative approach. It was identified that the main impact was caused by tourists staying at the homes of friends and relatives, that is, generating significantly less impacts on the hotel sector and tourist attractions.
\end{abstract}

\footnotetext{
${ }^{1}$ Doutora em Geografia pela Universidade Federal Fluminense (UFF), docente do curso de Turismo da Unemat - Nova Xavantina. E-mail: ritagarcia@unemat.br

${ }^{2}$ Doutor em Administração pela Universidade Federal de Minas Gerais (UFMG), docente do curso de Turismo da Unemat - Nova Xavantina

${ }^{3}$ Mestre em Desenvolvimento Regional pela Universidade Alves Faria (ALFA), docente do curso de Turismo da Unemat - Nova Xavantina

${ }^{4}$ Graduanda em Turismo pela Universidade do Estado de Mato Grosso (UNEMAT)
} 


\section{Contabilidade}

Keywords: Economic impacts of tourism, tourist expenditure, tourist event.

\section{INTRODUÇÃO}

A Organização Mundial do Turismo (UNWTO, 2019) pontua que o turismo internacional continua a superar a taxa de crescimento da economia global, mas o Brasil permanece ofuscado nesse cenário. Por outro lado, não é aconselhável desprezar o turismo interno, uma vez que "[...] a relação de receitas do turismo interno é cerca de nove vezes superior à do receptivo internacional, sendo que o país recebe apenas $0,47 \%$ do total de turistas internacionais mundiais e $0,35 \%$ de seus gastos" (Rabahy, 2019, p. 2).

Quanto ao Brasil, sua dimensão continental é diretamente proporcional às disparidades regionais. A Região Centro-Oeste contabilizou em 2018, 12.786.957 desembarques nacionais de passageiros e o Estado de Mato Grosso, 1.618 .096 ou 1,69\% do total de desembarques nacionais de passageiros (Brasil, 2019).

O número de desembarques de pessoas nos aeroportos é apenas um indicador do turismo. Estão disponíveis diversos instrumentos e métodos de análises para avaliação da economia, mas por outro lado, há uma carência de dados. Analisar os impactos econômicos do turismo pode auxiliar nas tomadas de decisões de investidores, instituições, empresários e gestores públicos, desde a escala global até a escala local.

O Brasil possui 5.565 municípios dos quais 3.914 possuem população de até 20.000 habitantes (IBGE, 2010). Uma vez que o Brasil possui numerosos municípios de pequeno porte onde o turismo se desenvolve e gera impactos desconhecidos, mas relevantes para os modos de vida da população regional e para as economias locais, pretende-se descrever características gerais do turista e do turismo em um pequeno destino turístico. Nestes lugares as políticas públicas ficam mais evidentes e seus resultados mais acessíveis para verificação e mensuração (Hall, 1989).

Segundo Baidal (2001), para conciliar objetivos de desenvolvimento econômico no turismo com a conservação e gestão responsável do território e dos recursos, se vem impulsionando iniciativas de investigações condizentes com a elaboração de métodos e técnicas, úteis para o planejamento e gestão, à escala regional e local, além disso, cumprir 
exigências ambientais e qualificar o turismo combinando objetivos sociais, econômicos e ambientais.

Reconhecendo que a escala local é onde as práxis são desencadeadas, o objetivo deste trabalho de maneira mais ampla, é estimar o impacto econômico do gasto direto dos turistas do evento rodeio de Nova Xavantina, Estado de Mato Grosso, nos anos de 2018 e 2019, e mais especificamente, identificar o perfil de gasto direto desses turistas com alojamento, alimentação, atrativos turísticos e evento; e, analisar diferentes perfis de permanência e gasto a partir do meio de hospedagem utilizado pelo turista na localidade receptora.

Os eventos são um importante motivador do turismo e figuram com destaque no desenvolvimento e planos de marketing da maioria dos destinos (Getz, 2008) e à medida que o destino se especializa e oferece condições logísticas, recursos humanos especializados, tecnologia e capacidade de acolher visitantes, estará apto a ingressar no mercado de turismo de eventos.

É consenso que toda atividade deve ser analisada em suas nuances para que a sociedade e seus governantes avaliem e tenham condições de discernir aquilo que consideram relevante e em que medida. A dimensão econômico-financeira, é de longe a mais investigada no turismo embora não seja a única - haja vista o destaque para pesquisas no setor de eventos, sejam eles megaeventos ou hallmark (Hall, 1989) ou eventos de menor porte (Egresi \& Kara, 2014).

Wallstam, Ioannid e Petterson (2018) apontam para a falta de indicadores sociais para avaliar os destinos turísticos e chegam a apontar que os eventos não tem o efeito econômico prometido, nesse sentido estudos como de Gonzàlez-Reverté e Morales-Pérez (2017) investigam a relação entre eventos turísticos e a percepção do seu impacto social e cultural. As análises sociais, ambientais, culturais e econômicas devem servir como instrumentos de apoio a decisões relativas ao turismo, sejam referentes aos setores público, privado ou à comunidade.

Crompton e Mckay (1994, citados por Perles-Ribes \& Díaz-Sánchez, 2019) e Quinn (2009) afirmam que várias pesquisas de impacto econômico de eventos objetivaram mensurar o desenvolvimento, pelo menos parcialmente inspirado nas realidades do governo municipal e regional, a partir de suas necessidades para justificar o investimento em estratégias de desenvolvimento de festivais e eventos. Outro aspecto é apontado por Barbosa, Martelotte e Zouain (2006, p. 398): “existe uma tendência, por parte dos órgãos públicos responsáveis pelo 


\section{Contabilidade}

desenvolvimento do setor de turismo no Brasil, de não utilizar pesquisas e estudos técnicos para balizar suas ações, [...] o que possibilitaria uma minimização de possíveis erros”.

Por sua vez, Stynes (1999) aponta que para analisar os impactos econômicos do turismo, em específico pela promoção de eventos, deve-se considerar os custos para realização do evento, os investimentos em infraestrutura e os custos suportados pela comunidade. "As decisões corretas baseiam-se em uma avaliação equilibrada e objetiva dos benefícios e custos e na compreensão de quem se beneficia do turismo e quem paga por ele" (Stynes, 1999, p.1).

Inevitavelmente, a ascensão dos eventos e do turismo está gerando uma maior necessidade de responsabilidade, transparência, e abrangência na avaliação de políticas, estratégias, investimentos e intervenções, conforme Getz e Page (2016).

\section{REFERENCIAL TEÓRICO}

\subsection{Eventos}

Nem todos os eventos são direcionados ao turismo (Getz, 2008), contudo receber turistas pode significar a injeção de dinheiro novo na economia local.

No passado os eventos eram criados por iniciativas individuais e comunitárias, mas tem se tornado um campo de atuação de profissionais e empresários (Getz \& Page, 2016), isso se deve a dimensão de serviços e produtos que são necessários:

[...] centros e espaços para eventos, serviços de catering, decoração, iluminação, cenografia, equipamentos multimídias, materiais gráficos, mídias digitais, montadoras, recursos humanos especializados (produtores, recepcionistas, seguranças, recreacionistas, artistas etc.), serviços logísticos de transporte e movimentação, seguros para eventos, e outros tão diversos quanto a criatividade empregada no planejamento de um evento (Gayer, 2017, p. 12).

Para atrair visitantes para um evento, seja um fluxo regional, nacional ou internacional é indispensável dispor de um sistema turístico capaz de atender a demanda por serviços de alimentação, alojamento, transporte, atrações, entre outros, por um determinado tempo (permanência do turista no destino). Outro fator relevante e que influencia diretamente no fluxo de turistas para um destino são as condições da infraestrutura de acesso (Gayer, 2017).

No turismo, os eventos têm a função de melhorar a oferta de destino, expandir o potencial turístico e a capacidade dos destinos (além de um foco estreito no lazer), e reduzir a sazonalidade (Getz \& Page, 2016). 


\section{Contabilidade}

É recorrente na literatura análises econômicas, sociais, culturais e ambientais acerca de eventos de maior porte ou megaeventos e sua relação com o turismo, enquanto eventos menores raramente despertaram o interesse de pesquisadores (Mckercher et al., 2006; Nurse, 2001; Quinn, 2009; Baptista et al., 2010, citados por Egresi \& Kara, 2014). Os autores justificam que eventos menores, normalmente são organizados por agentes locais e atraem menos turistas. Barajas, Coates e Sanchez-Fernandez (2016) apontam para a dificuldade de coleta de dados devido ao fato de que em pequenos eventos em pequenas cidades, o poder de atrair turistas é menor.

Diante da capacidade dos eventos de gerar benefícios nos destinos turísticos, várias pesquisas estiveram voltadas ao dimensionamento de seus impactos econômicos, a exemplo no Brasil, dos estudos realizados por Moraes (2012), Monteiro e Marques (2015) e Scabrini e Dalonso (2018); estimação do impacto econômico gerado por festas populares na Espanha por Perles-Ribes e Díaz-Sánchez (2019); e, estudo do impacto econômico de eventos esportivos em pequenas cidades, por Barajas, Coates e Sanchez-Fernandez (2016), dentre outros.

\subsection{Impacto Econômico dos Eventos}

Segundo Quinn (2009) à medida que os eventos foram se incorporando às agendas de desenvolvimento urbano e regional, houve crescimento do interesse acadêmico por mensurar o seu impacto econômico intimamente ligado às necessidades dos organizadores e promotores.

Para Matheson e Baade (2006) os gastos diretos devem ser o ponto de partida para o cálculo de impacto econômico de eventos e posteriormente calcula-se o retorno sobre o investimento público. A falta de multiplicadores precisos ou apropriados para a área geográfica do estudo é superada, além disso, o risco de exagerar o impacto econômico é reduzido.

Stynes (1997) menciona três tipos de impactos econômicos: diretos, indiretos e induzidos. Segundo ele, os impactos diretos são aqueles derivados de despesas turísticas que geram mudanças no nível de produção nos serviços turísticos, o gasto que turistas fazem em hotéis, restaurantes e atrativos, dentre outros. Impactos indiretos acontecem quando essas prestadoras de serviço turístico utilizam os recursos advindos dos turistas para fazer compras com fornecedores de produtos e serviços, enquanto os impactos induzidos dizem respeito às mudanças na atividade econômica resultantes dos gastos das famílias com a renda auferida direta ou indiretamente como resultado dos gastos com turismo, a exemplo dos gastos domésticos dos funcionários assalariados das empresas turísticas. 


\section{Contabilidade}

\section{METODOLOGIA}

\subsection{O evento Rodeio}

A coleta de dados ocorreu junto aos participantes do evento Rodeio, denominado NX Rodeio Music. O rodeio é fruto da relação entre esporte (montaria em touros e cavalos), festa, entretenimento e animação cultural, realizado por empresa ou associação, envolve despesas e contratações com altos valores. Os principais campeonatos de rodeio são realizados nos cinco países com maior tradição para a montaria: Estados Unidos, Canadá, México, Austrália e Brasil (Moraes, Santos \& Pimentel, 2015). O maior evento brasileiro desta modalidade é a Festa do Peão de Barretos, iniciada em 1956 na cidade de Barretos (SP), que recebe aos finais de semana 950 mil pessoas (Moraes, 2012).

O NX Rodeio Music é uma nova versão da Festa de Peão realizada, há mais de uma década no município, passou a ter nova denominação devido a ênfase nos shows com artistas nacionais no rol da programação do evento.

Ao considerar as quatro tipologias de eventos de Getz e Page (2016) (negócios, festivais e cultura, entretenimento e esportivos), o NX Rodeio Music é classificado como de entretenimento, uma vez que se caracteriza por proporcionar divertimento aos participantes, ser popular e promovido pelo setor privado, com fins lucrativos.

O evento pesquisado é realizado no município de Nova Xavantina - MT, situado na Região de Barra do Garças, extremo leste do estado. Essa região, de acordo com o Zoneamento Socioeconômico Ecológico do Estado de Mato Grosso (ZSEE/MT) de 2018, contabiliza 26 municípios. Nova Xavantina possui uma população estimada em 20.944 pessoas e serviços foi a principal atividade econômica em 2017 (IBGE, 2020).

\subsection{A pesquisa}

O estudo é uma análise de impacto econômico com pesquisa de gastos com visitantes, conforme a taxonomia proposta por Stynes (1997, 1999) para classificação de análises econômicas. O método de levantamento de gastos permite identificar como se deram os gastos diretos dos turistas em atividades típicas do turismo na localidade receptora durante a realização do evento para posterior estimação do impacto econômico desse gasto no trade local.

A investigação se classifica como descritiva com abordagem quantitativa de análise dos dados obtidos. As principais características das pesquisas quantitativas são o uso de perguntas 
baseadas em instrumento predeterminado e a busca por dados de desempenho, de atitude, observacionais e de censo, capazes de análise estatística (Creswell, 2007). Assim, esse método visa estabelecer relações causais entre variáveis, buscando verificar resultados por meio de objetivos previamente definidos (Minayo, Souza \& Santos, 2005).

O instrumento de coleta de dados utilizado teve como objetivo identificar o perfil dos turistas quanto à idade, gênero, estado civil, renda, escolaridade; quanto à visita: origem, meio de transporte, finalidade da visita, duração da estada, meio de hospedagem utilizado; e, quanto a despesa total dos turistas, incluindo gastos no próprio evento, com hospedagem, alimentação, atrativos locais e gastos de outra natureza, contudo serão apresentados e discutidos os gastos diretos dos turistas e analisados os perfis de permanência e gastos a partir do meio de hospedagem utilizado pelo turista durante o evento na Região de Barra do Garças (MT).

Para elaboração deste trabalho percorreram-se algumas etapas principais (em alguns casos simultâneas): pesquisa bibliográfica em artigos e livros; elaboração do instrumento de coleta de dados; solicitação de autorização aos organizadores do evento para coleta de dados durante o evento; treinamento dos pesquisadores (acadêmicos do Curso de Bacharelado em Turismo da Universidade do Estado de Mato Grosso); aplicação dos formulários durante o evento (em 2018 e 2019); averiguação dos formulários aplicados - é importante mencionar que, apesar do treinamento, um número significativo de formulários foi descartado devido a erros de preenchimento -; tabulação dos dados; exclusão de formulários fora do padrão geral das respostas ${ }^{5} ; \mathrm{e}$, análise dos dados.

\subsection{Amostra e coleta de dados}

A coleta de dados se deu com a aplicação de formulário junto aos frequentadores do evento, antes de ingressarem no recinto, por pesquisadores que faziam os questionamentos e registravam as respostas obtidas sendo admitido apenas um formulário por turista por edição do evento.

Inicialmente, realizou-se a triagem dos participantes do evento com o questionamento sobre a cidade de origem e a duração da estada. Deste modo, foi possível identificar membros

\footnotetext{
${ }^{5}$ Os outliers foram definidos com base na duração da estadia do turista na localidade, sendo excluídos aqueles cuja permanência foi superior a 30 dias. Por esse critério foram desconsiderados cinco respondentes nas duas edições do evento.
} 


\section{Contabilidade}

da comunidade local e excursionistas ${ }^{6}$, os quais não foram foco da pesquisa. Aos respondentes, a garantia de anonimato.

O objetivo dos pesquisadores consistiu em abordar e entrevistar o maior número possível de pessoas na chegada ao local do evento, reconhecendo que a coleta censitária não seria possível apesar de tratar de um evento local ou regional ${ }^{7}$. Como o evento ocorreu em recinto fechado e a entrada ocorreu por uma única portaria de acesso, os pesquisadores puderam observar e abordar as pessoas que iriam ingressar no local do evento com tranquilidade. $\mathrm{O}$ número total de pessoas que participaram diariamente do evento foi fornecido pelos organizadores.

Seguindo a tabela de amplitude de uma amostra tirada de uma população finita apresentada por Arkin e Colton (1963, citados por Tagliacarne, 1976), com margens de erro de $1 \%, 2 \%, 3 \%, 4 \%, 5 \%$ ou $10 \%$ e coeficiente de confiança de $95,5 \%$, verificou-se que a margem de erro para o ano de 2018 foi de $2 \%$. Em 2019, o coeficiente de confiança foi de $99,7 \%$ com margem de erro de $1 \%$.

A Tabela 1 apresenta as principais características da amostra de pesquisa nas duas edições do evento pesquisadas. A coleta de dados ocorreu nos dias 18 e 19 de maio de 2018, e entre $1^{\circ}$ e 4 de maio de 2019.

\footnotetext{
${ }^{6}$ Excursionista é aquele visitante que permanece menos de 24 horas na localidade (Cooper et al., 2001).

${ }^{7}$ Os eventos locais e regionais são fixos em determinado local e atraem principalmente os residentes (Getz \& Page, 2016).
} 


\section{Contabilidade}

Tabela 1: Características da amostra de pesquisa

\begin{tabular}{lcr}
\hline \multicolumn{1}{c}{ Item } & $\mathbf{2 0 1 8}$ & $\mathbf{2 0 1 9}$ \\
\hline Número de frequentadores do evento & 8.700 & 14.931 \\
\hline Amostra de pesquisa & 1.955 & 7.764 \\
\hline $\begin{array}{l}\text { Percentual da amostra em relação aos frequentadores } \\
\text { do evento nos dias de pesquisa }\end{array}$ & $22,5 \%$ & $52,0 \%$ \\
\hline Total de turistas na amostra & 137 & 207 \\
\hline Percentual de turistas na amostra & $7,0 \%$ & $2,7 \%$ \\
\hline Estimativa de turistas presentes no evento & 610 & 398 \\
\hline
\end{tabular}

Fonte: Dados da pesquisa $(2018,2019)$

Nota-se que nas duas edições do evento a amostra correspondeu a uma parcela significativa do universo pesquisado, e as estimativas no que tange à mensuração do impacto econômico direto dos gastos dos turistas permitirão inferências relevantes para um evento.

\section{$3.4 \mathrm{O}$ cálculo do impacto econômico do gasto direto dos turistas}

Inicialmente, calculou-se o percentual de turistas por tipo de meio de hospedagem utilizado no decorrer do evento, o tempo médio de permanência desse turista na localidade e seu gasto direto médio diário, estratificados pelo meio de hospedagem utilizado. Em seguida, o gasto médio diário foi subdividido em quatro categorias analíticas correspondentes aos principais tipos de despesa turística para os frequentadores do evento: alojamento, alimentação, evento e atrativos e passeios, também levando em conta o meio de hospedagem.

Posteriormente, foi estimado o número total de turistas presentes no evento considerando o percentual de turistas na amostra de pesquisa e o público total do evento, o qual foi disponibilizado pelo organizador dos eventos. Finalmente, o impacto econômico do gasto direto foi estimado considerando as Fórmulas (1) e (2).

$I E_{k}=\left(p_{m o} * P\right) * G m_{k}$

Onde:

$I E_{k}=$ Impacto econômico do gasto direto por categoria analítica

$p_{m o}=$ Percentual de turistas por meio de hospedagem utilizado 
$P=$ Público presente no evento

$G m_{k}=$ Gasto médio diário do turista por categoria analítica

$k=$ Alojamento, alimentação, evento e atrativos e passeios

$I E_{T}=\sum I E_{k}$

Onde:

$I E_{T}=$ Impacto econômico total do gasto direto dos turistas

$I E_{k}=$ Impacto econômico do gasto direto em cada categoria analítica

$k=$ Alojamento, alimentação, evento e atrativos e passeios

Os dados coletados foram lançados em arquivo do banco de dados Access e posteriormente exportados para planilhas Excel para realização dos cálculos.

Com isso, foi possível conhecer o perfil de permanência e gasto dos turistas presentes no evento e estimar o impacto econômico dos gastos diretos desses turistas com atividades típicas do turismo, os quais são apresentados a seguir.

\section{ANÁLISE E DISCUSSÃO DOS RESULTADOS}

Na região de destino turístico se encontra o maior dinamismo da atividade turística pelas relações que são estabelecidas entre os agentes do turismo, e principalmente pelos produtos e serviços ofertados, são eles: meios de hospedagem, alimentos e bebidas, animação turística, atrativos turísticos, eventos, shopping e outros serviços (Leiper, 2004). Dentre os serviços apresentados, optou-se por identificar o meio de hospedagem utilizado pelos turistas (vide Tabela 2) uma vez que a partir da relação entre meios de hospedagem, tempo de permanência e gasto médio diário é possível chegar a uma estimativa dos impactos econômicos do turismo em dado destino turístico. 
Tabela 2: Características do turista por tipo de meio de hospedagem utilizado (2018)

\begin{tabular}{lccr}
\hline Meio de hospedagem & Percentual de turistas & Permanência média & Gasto médio diário \\
\hline Hotel & $20,2 \%$ & 2,3 & 450,20 \\
\hline A\&P & $75,8 \%$ & 2,7 & 242,79 \\
\hline Casa própria & $4,0 \%$ & 21,0 & 344,33 \\
\hline Outros & - & - & - \\
\hline
\end{tabular}

Fonte: Dados da pesquisa (2018)

Tabela 3: Características do turista por tipo de meio de hospedagem utilizado (2019)

\begin{tabular}{lccc}
\hline Meio de hospedagem & Percentual de turistas & Permanência média & Gasto médio diário \\
\hline Hotel & $19,2 \%$ & 3,3 & 777,75 \\
\hline A\&P & $75,8 \%$ & 5,6 & 298,63 \\
\hline Casa própria & $3,3 \%$ & 4,5 & 560,00 \\
\hline Outros & $1,7 \%$ & 2,5 & 180,00 \\
\hline
\end{tabular}

Fonte: Dados da pesquisa (2019)

Percebe-se nas Tabelas 2 e 3 que a casa de amigos e parentes (A\&P) é o principal meio de hospedagem utilizado pelos turistas que frequentaram o evento, tanto em 2018, quanto em 2019. Também é possível verificar que esse grupo de turistas dobrou seu tempo de permanência na localidade de um ano para o outro, de uma permanência média de 2,7 dias para 5,6 dias.

A pesquisa publicada pela Fundação Instituto de Pesquisas Econômicas em 2012, apontou que $62,8 \%$ dos turistas em viagens domésticas no Brasil, optaram pelo meio de hospedagem casa de amigos e parentes, $25 \%$ optaram por hotel, pousada ou resort, $3,7 \%$ por casa própria e $8,5 \%$ por outro tipo de meio de hospedagem, e a permanência média em dias no destino, independentemente da motivação, foi de 10 dias (FIPE, 2012). Os dados coletados no Rodeio em Nova Xavantina indicam uma maior propensão à hospedagem na casa de amigos e parentes e permanência média inferior à média nacional para este tipo de turismo. 


\section{Contabilidade}

Apesar do estudo de Rabahy, Santos e Vassalo (2009) inferir que quanto maior a duração da viagem, menor o gasto turístico diário por pessoa, o mesmo não foi observado no evento de Nova Xavantina (MT), com exceção do alojamento em casa própria que teve redução no tempo de permanência e aumento no gasto médio diário.

Nota-se também a ocorrência de aumento significativo no gasto direto médio dos turistas em todas as categorias de 2018 para 2019. Esse aumento correspondeu a 73\% para os que se hospedaram na rede hoteleira, $23 \%$ para aqueles que se alojaram na casa de amigos e parentes e $63 \%$ para os que se hospedaram em casa própria. Tal acréscimo é bem superior à inflação registrada no período, que foi de 4,66\%, conforme o Índice Nacional de Preços ao Consumidor Ampliado (IPCA) (IBGE, 2020).

O que se percebe é uma redução no número de turistas participantes do evento de um ano para outro, como apresentado na Tabela 1, contudo houve elevação dos gastos. A estratificação dos dados referentes ao gasto direto dos turistas em diferentes serviços característicos da atividade turística é apresentada nas Tabelas 4 e 5.

Tabela 4: Perfil de gasto direto médio do turista por tipo de meio de hospedagem (2018)

\begin{tabular}{lrrrrr}
\hline $\begin{array}{c}\text { Meio de } \\
\text { hospedagem }\end{array}$ & Alojamento & Alimentação & Evento & $\begin{array}{c}\text { Atrativos e } \\
\text { passeios }\end{array}$ & Gasto total \\
\hline Hotel & 132,50 & 88,83 & 214,07 & 14,80 & 450,20 \\
\hline A\&P & - & 40,94 & 184,67 & 17,18 & 242,79 \\
\hline Casa própria & - & 48,33 & 176,00 & 120,00 & 344,33 \\
\hline Outros & - & - & - & & - \\
\hline
\end{tabular}

Fonte: Dados da pesquisa (2018) 


\section{Contabilidade}

Tabela 5: Perfil de gasto direto médio do turista por tipo de meio de hospedagem (2019)

\begin{tabular}{lrrrrr}
$\begin{array}{c}\text { Meio de } \\
\text { hospedagem }\end{array}$ & Alojamento & Alimentação & Evento & Atrativos e & Gasto total \\
passeios & & & \\
\hline Hotel & 141,52 & 90,65 & 519,13 & 26,45 & 777,75 \\
\hline A\&P & 1,10 & 69,89 & 201,81 & 25,83 & 298,63 \\
\hline Casa própria & - & 157,50 & 277,50 & 125,00 & 560,00 \\
\hline Outros & - & - & 180,00 & & 180,00 \\
\hline
\end{tabular}

Fonte: Dados da pesquisa (2019)

Houve aumento em todos os gastos diretos médios dos turistas, sendo que o mais significativo foi o gasto no próprio evento por aqueles hospedados na rede hoteleira. Algumas variáveis podem explicar o aumento nos gastos diretos dos turistas, uma delas é a renda mensal.

Em 2018, a mediana da renda individual mensal do turista, correspondeu a $\mathrm{R} \$ 2.170,00$ enquanto, em 2019, correspondeu a $\mathrm{R} \$ 3.000,00$; a mediana da renda familiar do turista para o mesmo período correspondeu, respectivamente, a $\mathrm{R} \$ 3.000,00$ e $\mathrm{R} \$ 4.990,00$. O acréscimo de $66 \%$ sobre a renda familiar, leva à hipótese de alteração do perfil dos turistas deste evento.

Dwyer, Forsyth e Spurr (2006) entendem que o montante das despesas dos visitantes é o principal insumo para avaliação de impactos econômicos, salientando que é o "dinheiro novo" que passa a circular na economia local que gera esse impacto.

Nesse sentido, o montante dos gastos diretos realizados na localidade se torna parte do impacto econômico total gerado pela atividade turística na localidade. O impacto econômico do gasto direto dos turistas na comunidade receptora com os principais serviços turísticos é apresentado nas Tabelas 6 e 7. 


\section{Contabilidade}

Tabela 6: Impacto econômico do gasto direto dos turistas por tipo de meio de hospedagem (2018)

\begin{tabular}{lccccc}
\hline $\begin{array}{c}\text { Meio de } \\
\text { hospedagem }\end{array}$ & Alojamento & Alimentação & Evento & Atrativos e & Total \\
passeios & & & \\
\hline Hotel & $16.286,48$ & $10.919,05$ & $26.312,37$ & $1.819,17$ & $55.337,06$ \\
\hline A\&P & - & $18.920,34$ & $85.346,86$ & $7.940,97$ & $112.208,18$ \\
\hline Casa própria & - & $1.188,16$ & $4.326,67$ & $2.950,00$ & $8.464,84$ \\
\hline Outros & - & & & & \\
\hline Total & $16.286,48$ & $31.027,55$ & $115.985,90$ & $12.710,14$ & $176.010,08$ \\
\hline
\end{tabular}

Fonte: Dados da pesquisa (2018)

Tabela 7: Impacto econômico do gasto direto dos turistas por tipo de meio de hospedagem (2019)

\begin{tabular}{lrrrrr}
\hline $\begin{array}{c}\text { Meio de } \\
\text { hospedagem }\end{array}$ & Alojamento & Alimentação & Evento & $\begin{array}{c}\text { Atrativos e } \\
\text { passeios }\end{array}$ & Total \\
\hline Hotel & $10.798,00$ & $6.916,69$ & $39.609,27$ & $2.018,05$ & $59.342,01$ \\
\hline A\&P & 331,74 & $21.098,40$ & $60.923,26$ & $7.798,35$ & $90.151,75$ \\
\hline Casa própria & - & $2.089,94$ & $3.682,27$ & $1.658,68$ & $7.430,88$ \\
\hline Outros & - & - & $1.194,25$ & & $1.194,25$ \\
\hline Total & $11.129,74$ & $30.105,03$ & $105.409,05$ & $11.745,08$ & $158.118,90$
\end{tabular}

Fonte: Dados da pesquisa (2019)

Nota-se que nas duas edições do evento o principal impacto foi causado pelos turistas alojados nas casas de amigos e parentes, visto que em termos relativos eles foram responsáveis por aproximadamente $64 \%$ do impacto econômico do gasto direto gerado em 2018 e por $57 \%$ do impacto de 2019, contudo, representaram 75,8\% dos turistas em ambas edições.

Já o maior impacto em termos absolutos se deu no próprio evento, embora tenha havido uma perda em termos absolutos de $\mathrm{R} \$ 10.576,85$ de 2018 para 2019, percebem-se impactos significativamente menores no setor de hotelaria e nos atrativos turísticos. 


\section{Contabilidade}

Como mencionado anteriormente, para realizar eventos e ampliar a sua capacidade de atrair participantes, há demanda pela aquisição de produtos e contratação de vários serviços (Gayer, 2017), no caso específico dos rodeios, há uma infraestrutura para atender as características do próprio evento onde serão prestados esses serviços: arena, estacionamento, barracas de alimentação, camarotes, camarim, currais, palco, parque de diversões, estandes, tenda de shows, entre outros (Moraes, Santos \& Pimentel, 2015).

Deste modo, cabe refletir sobre o fato de que muitas vezes parte significativa dos gastos realizados pelos turistas podem não gerar efeito econômico na comunidade receptora, em função de que os beneficiários desses gastos podem ser oriundos de outros municípios. Nesse sentido, Tyrrell e Johnston (2001), ao analisarem eventos turísticos norte-americanos, identificaram que pode ocorrer uma diferença significativa entre o impacto econômico bruto resultante dos gastos diretos dos turistas e o impacto econômico líquido na comunidade, em função da existência de mercadorias e serviços "importados". Assim, a identificação efetiva do benefício líquido passaria pela análise dos prestadores de serviço e comerciantes instalados no recinto do evento.

Gráfico 1: Evolução do impacto econômico do gasto direto por tipo de serviço turístico por meio de hospedagem utilizado pelo turista $(2018,2019)$

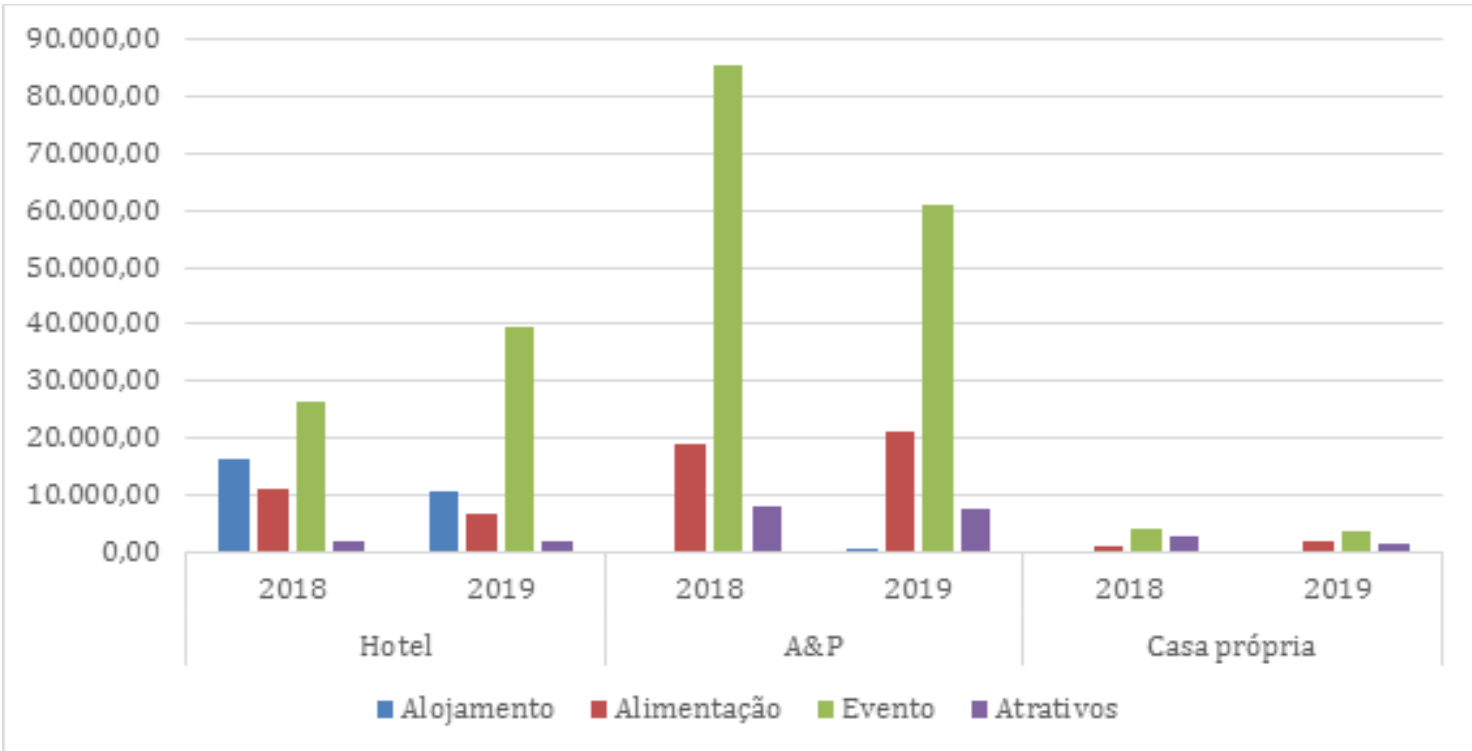

Fonte: Dados da pesquisa $(2018,2019)$ 


\section{Contabilidade}

É possível verificar mudanças no impacto do gasto direto gerado pelos turistas quando se comparam as duas edições do evento. Com respeito àqueles que se hospedaram na rede hoteleira local, houve redução do impacto econômico nos setores de hospedagem e alimentação, e aumento no próprio evento e nos atrativos turísticos. Tal redução pode estar associada à queda do número de turistas presentes no evento de 2019 em relação a 2018. Por outro lado, embora o número de turistas em 2019 tenha sido menor, houve aumento nos gastos no evento e nas visitas aos atrativos turísticos existentes no município, o que resultou em um maior impacto econômico em termos absolutos.

Os turistas que se hospedaram na casa de amigos e parentes (A\&P), o maior grupo, ampliou seu impacto econômico no setor de alimentação e nos atrativos de 2018 para 2019, enquanto diminuiu significativamente seu impacto direto no evento, uma redução de $40 \%$ em valores nominais. Já os turistas que se alojam em casa própria foram responsáveis por impacto econômico bastante reduzido quando comparado aos demais grupos de turistas.

Esses resultados são coerentes com Preuss, Könecke e Schütte (2010, citados por Barajas et al., 2016), os quais argumentam que somente os gastos dos participantes que ficam na cidade para o evento que devem ser levados em consideração como efeito positivo do turismo na localidade, e salientam que, para um pequeno evento em uma pequena cidade, o valor provável também é pequeno.

Quinn (2009) e Barajas, Coates e Sanchez-Fernandez (2016) observaram o reduzido poder de atração dos turistas por eventos de pequena escala realizados em pequenas cidades e observou-se no Rodeio de Nova Xavantina.

Por outro lado, diversos autores, a exemplo de Attanasi et al. (2013), Davis (2017), Jepson, Stadler e Spencer (2019), Pavlukovic, Armenski e Alcantara-Pilar (2017) e Wallstam, Ioaniddes e Pettersson (2018), pesquisam dimensões e indicadores de impactos sociais derivados de pequenos e médios eventos nas comunidades receptoras que justifiquem sua realização, mesmo não havendo viabilidade econômica.

\section{CONCLUSÕES}

Há uma tendência a subestimação das estatísticas em turismo uma vez que certos aspectos do comportamento do turista não são capturados/captados. Para que os impactos econômicos dos gastos diretos do turista fossem confiáveis, optou-se pela aplicação de 


\section{Contabilidade}

formulários no local do evento evitando que os turistas alojados em meios de hospedagem alternativo não fossem contabilizados, o que representaria uma omissão de 79,8\% em 2018 e 80,8\% em 2019 dos turistas e a subestimação dos gastos diretos.

Os eventos locais ou regionais, tem características peculiares, alguns assumem o propósito de entreter e/ou promover as manifestações culturais locais direcionadas às comunidades, outros estabelecem estratégias para atrair o turista e consequentemente solucionar problemas típicos da oferta turística em decorrência da sazonalidade da atividade, ajudar no desenvolvimento econômico e urbano. Assim, a pesquisa buscou contribuir, por meio da estimativa do gasto do turista, com os estudos de impacto econômico de eventos de pequena escala.

Para pensar o evento estrategicamente - seja local/regional, nacional ou internacional é ponto pacífico o acesso à informação. $\mathrm{O}$ volume e a qualidade das informações permitem avaliar os efeitos do evento sobre a comunidade bem como planejar os subsequentes. Em eventos que haja investimento público é imprescindível calcular o retorno econômico e social (arrecadação de impostos, geração de renda) e torná-lo acessível à comunidade.

O trabalho destaca os estudos de impacto econômico de eventos de pequena escala e estima de forma mais precisa os gastos diretos dos turistas em um rodeio na expectativa de colaborar com a reflexão sobre turismo e eventos que se realizam em regiões interioranas do Brasil, sobre os fluxos regionais e impactos econômicos.

\section{REFERENCIAS}

Attanasi, Giuseppe; Fortuna, Casoria; Centorrino, Samuele \& Urso, Giulia. (2013). Cultural investment, local development and instantaneous social capital: a case study of a gathering festival in the South of Italy. The Journal of Socio-Economics, 47, 228-247. https://doi.org/10.1016/j.socec.2013.05.014

Baidal, Josep A. Ivars. (2001). Planificación y gestión del desarrollo turístico sostenible: propuestas para la creación de un sistema de indicadores. Alicante: Universidad de Alicante. http://rua.ua.es/dspace/handle/10045/20506.

Barajas, Angel; Coates, Dennis \& Sanchez-Fernandez, Patricio. (2016). Beyond retrospective assessment. Sport event economic impact studies as a management tool for informing event organization. European Research on Management and Business Economics, Elsevier, Amsterdam, 22(3), 124-130. https://doi.org/10.1016/j.iedee.2015.05.001 


\section{Contabilidade}

Barbosa, Luiz Gustavo M.; Martelotte, Marcela Cohen \& Zouain, Debora Moraes. (2006). Os impactos econômicos do turismo no município do Rio de Janeiro e suas implicações no desenvolvimento local. Turismo - Visão e Ação, Itajaí, 8 (3), 397-409.

https://doi.org/10.14210/rtva.v8n3.p397-410

Brasil. Ministério do Turismo. (2019, dezembro). Anuário Estatístico de Turismo - 2019. 46, ano base 2018. Brasília. http://www.dadosefatos.turismo.gov.br/2016-02-04-11-53-05.html.

Cooper, Chris; Fletcher, John; Fuall, Alan; Gilbert, David \& Wanhill, Stephen. (2001). Turismo princípios e prática. São Paulo: Bookman.

Creswell, John W. (2007). Projeto de pesquisa: métodos qualitativo, quantitativo e misto. 2. ed. Porto Alegre: Artmed.

Davis, Andrew. (2017). It wasn't me, it was my festival me: the effect of event stimuli on attendee identity formation. Tourism Management, 61, 484-500.

https://doi.org/10.1016/j.tourman.2017.03.007

Dwyer, Larry; Forsyth, Peter \& Spurr, Ray. (2006). Assessing the economic impacts of events: a computable general equilibrium approach. Journal of Travel Research, 45(1), 59-66. https://doi.org/10.1177\%2F0047287506288907

Egresi, Istvan \& Kara, Fatih. (2014, novembro). Motives of tourists attending small-scale events: The case of three local festivals and events in Istanbul, Turkey. Geojournal of Tourism and Geosites, Oradea, 2(14), 93-110. http://gtg.webhost.uoradea.ro/PDF/GTG-22014/1_156_Egresi.pdf.

FIPE. Fundação Instituto de Pesquisa Econômica. (2012). Caracterização e dimensionamento do turismo doméstico no Brasil - 2010/2011. Relatório executivo - produto 6. São Paulo: FIPE; Brasília: Ministério do Turismo. www.dadosefatos.turismo.gov.br.

Gayer, Priscila. (2017, dezembro). Políticas públicas em turismo de eventos: instrumentos normativos de apoio ao desenvolvimento do setor. Cenário - Revista Interdisciplinar em Turismo e Território, Brasília, 5(9), 11-22. https://doi.org/10.26512/revistacenario.v5i9.19425

Getz, Donald. (2008). Event tourism: definition, evolution, and research. Tourism Management, 29, 403-428. https://doi.org/10.1016/j.tourman.2007.07.017

Getz, Donald \& Page, Stephen J. (2016). Progress and prospects for event tourism research. Tourism Management, 52, 593-631. https://doi.org/10.1016/j.tourman.2015.03.007

Gonzàlez-Reverté, Francesc \& Morales-Pérez, Soledad. (2017). El impacto cultural y social de los eventos celebrados en los destinos turísticos. Percepción desde el punto de vista de los organizadores. Cuadernos de Turismo, Murcia, 40, 339-362.

https://doi.org/10.6018/turismo.40.309741 
Hall, Colin Michel. (1989). The definition and analysis of hallmark tourist events.

Geojournal, Kansas, 19(3), 263-269. https://doi.org/10.1007/BF00454570

IBGE. Instituto Brasileiro de Geografia e Estatística. (2010). Censo demográfico 2010. Principais resultados - sinopse. https://www.ibge.gov.br/estatisticas/sociais/populacao/2098np-censodemografico/9662-censo-demografico-2010.html?=\&t=destaques.

IBGE. Instituto Brasileiro de Geografia e Estatística. (2020). IBGE cidades. https://cidades.ibge.gov.br/brasil/mt/nova-xavantina/panorama.

IBGE. Instituto Brasileiro de Geografia e Estatística. Inflação. https://www.ibge.gov.br/estatisticas/economicas/precos-e-custos/9256-indice-nacional-deprecos-ao-consumidor-amplo.html?t=series-

historicas\&utm_source=landing\&utm_medium=explica\&utm_campaign=inflacao\#plano-realmes.

Jepson, Allan; Stadler, Raphaela \& Spencer, Neil. (2019). Making positive family memories together and improving quality-of-life through thick sociality and bonding in local community festivals and events. Tourism Management, 75, 34-50.

https://doi.org/10.1016/j.tourman.2019.05.001

Leiper, N. (2004). Tourism management. French Forest, NSW: Pearson Education Australia.

Matheson, Victor A. \& Baade, Robert A. (2006). Padding required: assessing the economic impact of the Super Bowl. European Sport Management Quarterly, 6.

https://doi.org/10.1080/16184740601154490

MATO GROSSO. Secretaria de Estado de Planejamento e Coordenação Geral. (2018). Mapas. Regiões de planejamento. Mapa Planejamento Região IV - Barra do Garças. Cuiabá. http://www.seplan.mt.gov.br/-/10950800-mapas.

Minayo, Maria Cecília de Souza; Souza, Edinilsa Ramos de \& Santos, Nilton José dos. (2005). Métodos, técnicas e relações em triangulação. In: Minayo, Maria Cecília de Souza; Assis, Simone Gonçalves de \& Souza, Ednilsa Ramos de. Avaliação por triangulação de métodos: abordagem de programas sociais. Rio de Janeiro: Fiocruz, 71-103. https://www.arca.fiocruz.br/handle/icict/1857.

Monteiro, João Evangelista Dias \& Marques, Osiris Ricardo Bezerra. (2015) A Jornada Mundial da Juventude 2013: os impactos econômicos dos gastos dos peregrinos na Cidade do Rio de Janeiro. Tourism \& Management Studies, 11(2), 71-77. http://dx.doi.org/10.18089/tms.2015.11209

Moraes, Adriana Gomes (2012). Turismo de eventos: un análisis del impacto económico en el comercio de la ciudad de Barretos (Brasil) durante la fiesta del peón rural. Revista Estudios y Perspectivas en Turismo, Buenos Aires, 21, 1594-1608.

https://www.estudiosenturismo.com.ar/ 


\section{Contabilidade}

Moraes, Jean Cléverson; Santos, Silvana \& Pimentel, Giuliano Gomes de Assis. (2015). Festa do esporte: a construção do entretenimento no rodeio. Revista Brasileira de Estudos do Lazer, Belo Horizonte, 2(3), 3-16. https://periodicos.ufmg.br/index.php/rbel/article/view/504.

Pavlukovic, Vanja; Armenski, Tanja \& Alcantara-Pilar, Juan Miguel. (2017). Social impacts of music festivals: Does culture impact locals' attitude toward events in Serbia and Hungary? Tourism Management, 63, 42-53. https://doi.org/10.1016/j.tourman.2017.06.006

Perles-Ribes, José Vicente \& Díaz-Sánchez, Elena. (2019). Reestimación del impacto de las fiestas populares de proyección turística a través de metadados provenientes de la telefonia móvil: Calp, un ejemplo de aplicación. Revista Pasos - Revista de Turismo y Patrimonio Cultural, Islas Canarias, 17(5), 947-961. https://doi.org/10.25145/j.pasos.2019.17.067

Quinn, Bernadette. (2009). Festivals, events and tourism. In: Jamal, Tazim \& Robinson, Mike (ed.). The Sage handbook of tourism studies. London: Sage, 483-503. http://dx.doi.org/10.4135/9780857021076.n27

Rabahy, Wilson Abrahão; Santos, Glauber Eduardo de Oliveira \& Vassalo, Moisés Diniz. (2009). Determinantes de gasto em viagens turísticas domésticas no brasil. Turismo - Visão e Ação, Itajaí, 11(3), 304-324. https://doi.org/10.14210/rtva.v11n3.p304-324

Rabahy, Wilson Abrahão. (2019). Análise e perspectivas do turismo no Brasil. Revista Brasileira de Pesquisa em Turismo, São Paulo, 14(1), 1-13. https://doi.org/10.7784/rbtur.v14i1.1903

Scabrini, Elaine Cristina Borges \& Dalonso, Yoná da Silva. (2018). Impactos dos eventos em destinos turísticos: um estudo de caso na cidade de Joinvile - SC. Revista Turismo em Análise, São Paulo, 29(2), 332-348. https://doi.org/10.11606/issn.1984-4867.v29i2p332-348

Stynes, Daniel J. (1999). Approaches to estimating the economic impacts of tourism: some examples. Cooperative Extension Service Bulletin. Urbana, IL: University of Illinois. https://msu.edu/course/prr/840/econimpact/pdf/ecimpvol2.pdf.

Stynes, Daniel J. (1997). Economic impacts of tourism. Cooperative Extension Service Bulletin. Urbana, IL: University of Illinois.

https://msu.edu/course/prr/840/econimpact/pdf/ecimpvol1.pdf.

Tagliacarne, Guglielmo. (1976). Pesquisa de mercado. São Paulo: Atlas.

Tyrrell, Timothy J.; Johnston, Robert J. (2001). A framework for assessing direct economic impacts of tourist events: distinguishing origins, destinations and causes of expenditures.

Journal of Travel Research, 40 (1), 94-100.

https://doi.org/10.1177\%2F004728750104000112

UNWTO. World Tourism Organization. (2019). International tourism highlights. http://dadosefatos.turismo.gov.br/ 


\section{Contabilidade}

Wallstam, Martin; Ioannid, Dimitri; Petterson, Robert. (2018). Evaluating the social impacts of events: in search of unified indicators for effective policymaking. Journal of Policy

Research in Tourism, Leisure and Events. https://doi.org/10.1080/19407963.2018.1515214. 